\title{
Complicações e taxa de recidiva em pacientes com carcinoma epidermóide da vulva tratadas com vulvectomia radical com uma ou três incisões: estudo de 132 casos
}

\author{
Complications and relapse rate in patients with vulvar squamous cell carcinoma undergoing \\ radical vulvectomy with one or three incisions: study of 132 cases
}

Luiz Antonio Verdiani, Sophie Françoise Mauricette Derchain

\begin{abstract}
RESUM0
O objetivo deste estudo foi comparar as taxas de complicações pós-operatórias e a taxa de recidiva em 132 mulheres com carcinoma da vulva tratadas com vulvectomia radical $e$ linfadenectomia inguinal bilateral com uma ou três incisões. Foi um ensaio clínico retrospectivo não randomizado, incluindo 65 mulheres operadas por incisão única e 67 por três incisões, entre 1986 e 1996. Para análise estatística foram realizados os testes Exato de Fischer, QuiQuadrado, t de Student e regressão logística e curvas de sobrevida pelo método de KaplanMeyer, comparadas pelo teste de Wilcoxon, seguidas de regressão de Cox, com limite de 5\% de significância estatística. Os grupos foram semelhantes com relação à idade, tabagismo, presença de síndromes clínicas, tipo e grau histológico. Pacientes com neoplasia no estadio III foram mais freqüentes no grupo de incisão única e mais linfonodos livres no grupo de três incisões. As pacientes tratadas com três incisões apresentaram significativamente menos complicações pós-operatórias imediatas (76\% vs $92 \%, p<0,05)$, menos deiscências (72\% vs $92 \%, p<0,01)$, menor necessidade de procedimentos secundários (76\% vs $94 \%, p<0,01) e$ menor tempo de internação (média de 19,4 dias vs 38,7 dias, $p<0,001$ ). Ocorreram sete óbitos pós-operatórios: cinco no grupo tratado com incisão única e dois com três incisões. A taxa de recidiva foi significativamente menor nas operadas com três incisões (19\% vs 35\%, $p<0,01) e$ com linfonodos livres de doença (6\% vs $15 \%, p<0,01$ ). Após a regressão de Cox, apenas os linfonodos comprometidos influenciaram negativamente o tempo livre de doença. Concluímos que a vulvectomia por três incisões apresenta menos complicações que a incisão única, sem comprometer a eficácia terapêutica, independente do estádio da neoplasia.
\end{abstract}

PALAVRAS-CHAVES: Carcinoma da vulva. Complicações de cirurgia. Infecções cirúrgicas.

Área de Oncologia do Departamento de Tocoginecologia da Faculdade de Ciências Médicas da Universidade Estadual de Campinas

Correspondência: Luiz Antonio Verdiani

Rua Guido Pelliciari, 40 - Torres de São José

13.214-520 - Jundiaí - SP

Tel.: (019) 9712763 ou (011) 73925277

Trabalho apresentado à Faculdade de Ciências Médicas da UNICAMP para obtenção do Título de Mestre em Tocoginecologia; Vencedor do Prêmio FEBRASGO. Rio de Janeiro, novembro de 1997.
Introdução

O câncer de vulva corresponde a menos de $1 \%$ das neoplasias malignas da mulher e de 3 a $5 \%$ dos tumores genitais femininos ${ }^{1,2,5,10,22}$. O diagnóstico do câncer de vulva geralmente é feito quando já existe invasão e, nos países menos desenvolvidos, em estádios avançados. Os principais fatores relacionados com o diagnóstico 
tardio são a demora na procura por atendimento e a dificuldade de se estabelecer o diagnóstico definitivo. Nos países desenvolvidos, como Estados Unidos e Inglaterra, de 18,5 a 37,8\% das pacientes apresentam doença em estádios III ou IV quando do diagnóstico ${ }^{13}$. Porém, algumas casuísticas americanas, suecas e holandesas apresentam de 45 a $49 \%$ das pacientes com diagnóstico em estádios III e IV ${ }^{2,8}$. No Brasil, o diagnóstico tardio é ainda mais freqüente e a porcentagem de casos diagnosticados nos estádios III e IV variam entre 36 e $57 \%{ }^{1,19,22}$.

O câncer da vulva pode disseminar-se a partir do sítio inicial de três maneiras: invasão local de tecido adjacente ao tumor primário, podendo atingir grandes dimensões e invadir estruturas anatômicas vizinhas; embolização para linfonodos regionais, usualmente inguinais superficiais e profundos e eventualmente pélvicos; e por via hematogênica, muito raramente, atingindo pulmões, fígado e $\operatorname{ossos}^{5}$. A mais importante via de disseminação é a linfática, sendo fundamental o estudo histopatológico dos linfonodos regionais nos casos com tumores invasores ${ }^{16,17,20}$. Em relação à evolução da paciente, os fatores associados à determinação do prognóstico são: estádio da neoplasia, tamanho do tumor primário, profundidade de invasão, margem cirúrgica, disseminação para linfonodos e invasão extranodal ${ }^{9,11,17}$.

A cirurgia é universalmente aceita como a terapêutica com a qual se obtém os melhores resultados para o tratamento do câncer de vulva. Apresenta, porém, duas características marcantes: o grau elevado de mutilação a que a paciente é submetida e o pós-operatório com recuperação lenta e prolongada, em razão, principalmente, da complicação imediata mais comum decorrente da cirurgia: a deiscência da ferida cirúrgica. Foram descritas várias técnicas que podem ser empregadas na realização da vulvectomia radical com linfadenectomia inguinal. A técnica clássica é aquela descrita por Way e posteriormente modificada por Marshall, com ressecção em bloco por meio de incisão única, conhecida como "asa de borboleta" ou "vespertílio". É até hoje aceita como tratamento de eleição por muitos autores, principalmente nos estádios avançados ${ }^{15,23}$. Pequenas modificações, como a diminuição na extensão de pele ressecada foram ocorrendo com o tempo. Porém, desde 1981, muitos estudos descreveram uma técnica utilizando três incisões, uma para a vulva e uma para cada região inguinal, enfocando suas vantagens e desvantagens $^{6,10,12,14,18,20}$. A vantagem da incisão única é a menor incidência de recidivas pela retirada da ponte cutânea que permanece entre as três incisões, por onde passam as vias de drenagem linfática. A técnica de três incisões justifica-se pela menor incidência de complicações pós-operatórias, menor permanência hospitalar e taxa de sobrevida semelhante quando comparadas com as pacientes operadas por incisão única. Demonstrou-se que as recorrências podem ser controladas com uma nova intervenção cirúrgica local, sem prejuízo para o prognóstico das pacientes ${ }^{4,14}$.

O objetivo deste estudo foi comparar a taxa de complicações pós-operatórias imediatas e tardias e a taxa de recidiva em mulheres com carcinoma epidermóide da vulva tratadas com vulvectomia radical e linfadenectomia inguinal bilateral, segundo o tipo de incisão cirúrgica utilizada, controlados pelas características das pacientes e da neoplasia. Em relação às complicações imediatas foi avaliada a taxa de deiscência e/ou infecção da ferida cirúrgica, trombose, óbito, procedimentos secundários como curativos, debridamento, ressutura e rotação de retalho e o tempo de internação segundo o tipo de incisão. Finalmente foi avaliada a taxa de recidivas e o local de ocorrência, tempo livre de doença e sobrevida.

\section{Sujeitos e métodos}

Este estudo é um ensaio clínico-retrospectivo não-randomizado. Foram estudadas todas as pacientes atendidas e tratadas entre 1986 e 1996 no CAISM - UNICAMP que satisfaziam os critérios de seleção, perfazendo um total de 132 pacientes. Foram incluídas as pacientes portadoras de câncer de vulva confirmado histologicamente e submetidas ao tratamento cirúrgico com vulvectomia radical e linfadenectomia inguinal, entre janeiro de 1986 e dezembro de 1996 na Área de Oncologia Genital e Patologia Mamária do CAISM-UNICAMP, com prontuário completo. Foram excluídas do estudo as pacientes previamente tratadas com medicação antiblástica ou irradiação, operadas em outro serviço, com perda de seguimento ou com outros tumores malignos genitais, concomitantes ou não.

A cirurgia realizada consistiu numa vulvectomia radical até o plano músculoaponeurótico do diafragma urogenital e linfadenectomia inguinal superficial e profunda (femoral). A cirurgia com incisão única foi realizada pela técnica de Way e modificada por Marshall ${ }^{23}$, com retirada da peça em bloco através de incisão única que se extende de uma crista ilíaca a outra e envolve o monte de Vênus e vulva, protocolo do serviço até 1991. A vulvectomia com três incisões foi realizada pela técnica modificada de Taussig ${ }^{21}$ mediante de incisões separadas, sendo uma para a vulva e uma para cada região inguinal, adotada como protocolo pelo Serviço em 1992. 
As pacientes foram controladas segundo a idade, tabagismo, síndromes clínicas associadas como hipertensão, cardiopatia, diabetes e pneumopatias. Quanto às características do tumor, foram analisados o tipo e grau histológico, estádio patológico e estado linfonodal. Após controlar os grupos por essas variáveis confundidoras, foi realizada uma análise bivariada e múltipla correlacionando as complicações imediatas, procedimentos secundários necessários, tempo de internação, taxa de recidiva, tempo livre de doença e tempo de sobrevida segundo o tipo de incisão.

Os métodos estatísticos utilizados foram: Teste Exato de Fischer, Qui-Guadrado e t de Student para comparação de médias seguido de regressão logística. Para avaliação da taxa de recidiva foram elaboradas curvas de sobrevida pelo método de Kaplan-Meyer, comparadas pelo teste de Wilcoxon e submetidas à regressão múltipla pelo método de Cox, com limite de $5 \%$ de significância estatística ${ }^{7}$.

\section{Resultados}

De um total de 212 prontuários revisados, 132 satisfaziam os critérios de inclusão. As 132 pacientes incluídas no estudo estavam divididas quase igualmente entre os dois tipos de cirurgia: $65(49 \%)$ por incisão única e $67(51 \%)$ por três incisões. A média de idade global foi de 66,7 anos (DP $\pm 13,2$ ), sendo 66,8 para incisão única (DP \pm $12,6)$ e 66,5 para três incisões (DP $\pm 13,8$ ). O número de mulheres com mais de 70 anos foi maior no grupo de três incisões, mas a diferença não foi estatisticamente significativa.

Pouco menos de 20\% das mulheres eram fumantes, em ambos os grupos. Aproximadamente metade das mulheres apresentavam algum tipo de doença ou síndrome clínica. Predominou a hipertensão arterial, presente em $40 \%$ das pacientes com três incisões e $26 \%$ daquelas com incisão única, mas essa diferença não foi significativa. O número de mulheres diabéticas foi três vezes maior no grupo de mulheres tratadas por três incisões. O tipo histológico predominante foi o carcinoma epidermóide puro (95\%). Em relação ao grau histológico, mais da metade das pacientes apresentaram carcinomas bem diferenciados. Quando se comparou o $\mathrm{T}$ patológico (pT), observamos um predomínio significante de pT3 em pacientes operadas por incisão única. Notou-se também que metade das mulheres tratadas com incisão única apresentavam linfonodos negativos, enquanto que entre aquelas tratadas com incisões triplas essa proporção era de dois terços. Essas diferenças, porém, não atingiram significância estatística. Portanto, quando se considerou o estádio patológico, mais da metade dos casos eram estádio II. A percentagem de mulheres com diagnóstico em estádio I continuou muito baixa, 15\%. Em relação à distribuição por estádio segundo o tipo de incisão, houve quase duas vezes mais pacientes em estádio II no grupo tratado por três incisões, enquanto que no grupo tratado por incisão única encontrou-se mais que o dobro de pacientes em estádio III (Tabela 1).

Tabela 1- Distribuição percentual das mulheres segundo as variáveis de controle e o tipo de incisão.

\begin{tabular}{|c|c|c|c|c|}
\hline \multirow[b]{2}{*}{ Variável } & \multicolumn{4}{|c|}{ Incisão } \\
\hline & & 1 & 3 & $\mathbf{p}$ \\
\hline Fumante & & $12 / 65$ & $13 / 67$ & N.S. \\
\hline \multicolumn{5}{|l|}{ Presença de } \\
\hline síndromes clínicas & & $33 / 65$ & $36 / 67$ & N.S. \\
\hline Hipertensão & & 17 & 27 & 0,084 \\
\hline Cardiopatia & & 12 & 11 & N.S. \\
\hline Diabetes & & 3 & 11 & 0,054 \\
\hline Pneumopatia & & 5 & 4 & N.S. \\
\hline \multirow[t]{2}{*}{ Tipo histológico } & escamoso & $58 / 65$ & $67 / 67$ & 0,017 \\
\hline & misto & $7 / 65$ & - & \\
\hline \multirow[t]{3}{*}{ Grau histológico } & I & $27 / 65$ & $41 / 67$ & \\
\hline & II & $30 / 65$ & $21 / 67$ & \\
\hline & III & $8 / 65$ & $5 / 67$ & N.S. \\
\hline \multirow[t]{3}{*}{ Tumor } & pT1 & $13 / 65$ & $12 / 67$ & \\
\hline & pT2 & $31 / 65$ & $45 / 67$ & \\
\hline & pT3 & $21 / 65$ & $10 / 67$ & N.S. \\
\hline \multirow[t]{3}{*}{ Linfonodos } & pNo & $32 / 65$ & $43 / 67$ & \\
\hline & pN1 & $16 / 65$ & $10 / 67$ & \\
\hline & pN2 & $17 / 65$ & $14 / 67$ & N.S. \\
\hline \multirow[t]{4}{*}{ Estádio } & I & $14 / 65$ & $16 / 67$ & 0,6803 \\
\hline & II & $25 / 65$ & $47 / 67$ & ${ }^{*} 0,0093$ \\
\hline & III & $35 / 65$ & $16 / 67$ & ${ }^{*} 0,0127$ \\
\hline & IVa & 26 & 21 & 0,4761 \\
\hline
\end{tabular}

As complicações pós-operatórias imediatas ocorreram em $84 \%$ das mulheres operadas e foram significativamente mais freqüentes nas mulheres submetidas à vulvectomia com incisão única. A deiscência foi a complicação mais freqüente (83\%), com incidência estatisticamente menor nas mulheres tratadas com três incisões (73\% vs 92\%). A infecção ocorreu na mesma proporção nos dois grupos e não ocorreu nenhum caso de trombose. Sete mulheres morreram no pós-operatório imediato, sendo cinco entre as tratadas com incisão única e duas naquelas tratadas com três incisões. A necessidade de procedimentos secundários conseqüentes à cirurgia também foi alta: $85 \%$, sendo significativamente mais freqüente entre as 
mulheres submetidas à cirurgia por incisão única. Das pacientes operadas, $84 \%$ necessitaram de curativos especiais, mais da metade (51\%) de desbridamento, mais de um terço (35\%) de ressutura e $5 \%$ de rotação de retalho. Esses cuidados foram significativamente mais freqüentes nas mulheres tratadas com incisão única (Tabela 2).

Tabela 2 - Distribuição percentual das mulheres que apresentaram complicações pósoperatórias imediatas segundo o tipo de incisão.

\begin{tabular}{lllc}
\hline \multicolumn{3}{c}{ Incisão } & \\
Complicação & $\mathbf{1}$ & $\mathbf{3}$ & $\mathbf{p}$ \\
\hline *Presente & $60 / 65$ & $51 / 67$ & 0,021 \\
& & & \\
Deiscência & 60 & 50 & 0,007 \\
Infecção & 15 & 15 & N.S. \\
Óbito & 5 & 2 & N.S. \\
& & & \\
Procedimentos & $61 / 65$ & $50 / 67$ & 0,009 \\
& & & \\
Curativos & 61 & 49 & 0,005 \\
Debridamento & 39 & 29 & 0,054 \\
Ressutura & 29 & 17 & 0,020 \\
Retalho & 4 & 2 & N.S. \\
& & &
\end{tabular}

*Algumas pacientes apresentaram mais de uma complicação.

A permanência hospitalar foi duas vezes maior no grupo de incisão única. Enquanto as mulheres com três incisões tiveram média de internação de 19,4 dias ( $\mathrm{DP} \pm 11,7$ ), entre as mulheres com incisão única essa média foi de 38,7 dias ( $\mathrm{DP} \pm 22,3$ ). O maior tempo de permanência hospitalar das pacientes com incisão única foi estatisticamente significativo, com $\mathrm{p}<0,001$ (Figura I).

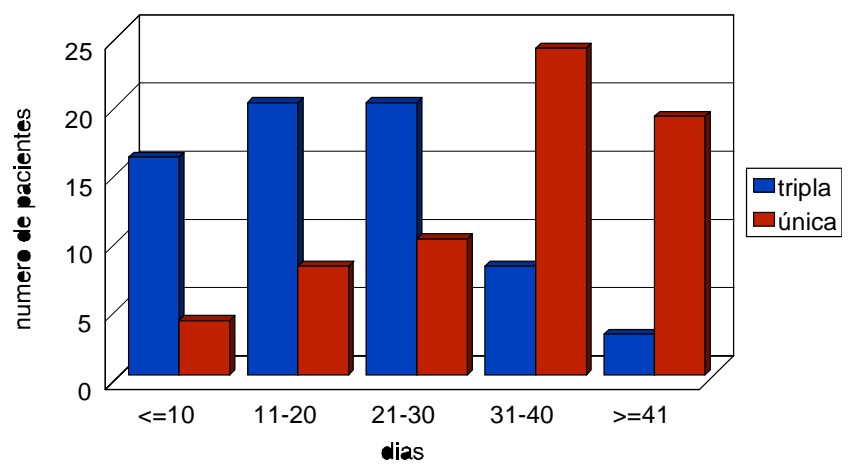

Figura 1 - Distribuição das mulheres segundo o tempo de internação.

$\mathrm{Na}$ primeira fase da regressão logística a significância do tempo de internação foi tão importante que excluiu as demais da análise final. Realizou-se então um segundo modelo de regressão logística, apenas com as variáveis categorizadas, excluindo o tempo de internação e foi observado que a necessidade de curativos especiais mantémse significativamente mais freqüente nas pacientes operadas por incisão única (Tabela 3).

Tabela 3 - Equação final dos fatores associados a complicações pós-operatórias segundo regressão logística.

\begin{tabular}{lccc}
\hline Variável & Coeficiente & Erro-padrão & Odds-ratio \\
Constante & $-1,6870$ & 0,580 & 0,185 \\
Curativos especiais & 1,6620 & 0,596 & 5,270 \\
\hline
\end{tabular}

Observou-se recidiva tumoral em $27 \%$ das pacientes, ocorrendo com freqüência quase duas vezes mais entre as pacientes tratadas por incisão única, sendo essa diferença estatisticamente significativa. Com relação ao local de recorrência, a recidiva vulvar foi quase duas vezes mais freqüente nas pacientes submetidas à incisão única. Nenhuma das pacientes submetidas à cirurgia por três incisões apresentou recidiva inguinal (Tabela 4).

Tabela 4 - Distribuição percentual das mulheres que apresentaram recidiva tumoral segundo o tipo de incisão.

\begin{tabular}{lccc}
\hline & \multicolumn{3}{c}{ Incisão } \\
Recidiva & $\mathbf{1}$ & $\mathbf{3}$ & $\mathbf{p}$ \\
\hline Presentes & $23 / 65$ & $13 / 67$ & 0,039 \\
& & & \\
Vulvar & 16 & 9 & N.S. \\
Inguinal & 4 & - & N.S. \\
Metástase & 3 & 4 & N.S. \\
\hline
\end{tabular}

A taxa acumulada de sobrevida livre de doença foi de $81 \%$ nas pacientes tratadas por três incisões e $65 \%$ naquelas tratadas por incisão única e essa diferença não foi estatisticamente significativa (Figura 2). Avaliando o tempo livre de doença segundo o estádio, observou-se uma melhora não-significativa da sobrevida nas mulheres submetidas a três incisões (Figuras 3 A, B, C, D). Verificou-se, também, que o melhor prognóstico foi apresentado pelas pacientes submetidas à cirurgia por três incisões quando os linfonodos estavam livres de neoplasia (Figura 4). Após a regressão logística, apenas a invasão linfonodal esteve significativamente associada ao tempo livre de doença e à taxa de sobrevida (Tabela 5). 


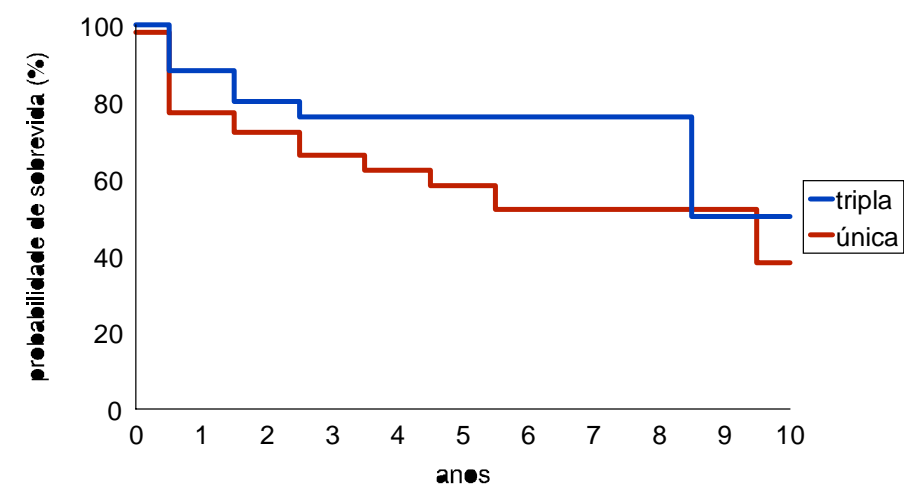

Figura 2 - Taxa acumulada de sobrevida livre de doença segundo o tipo de incisão $(p=0,5675)$.

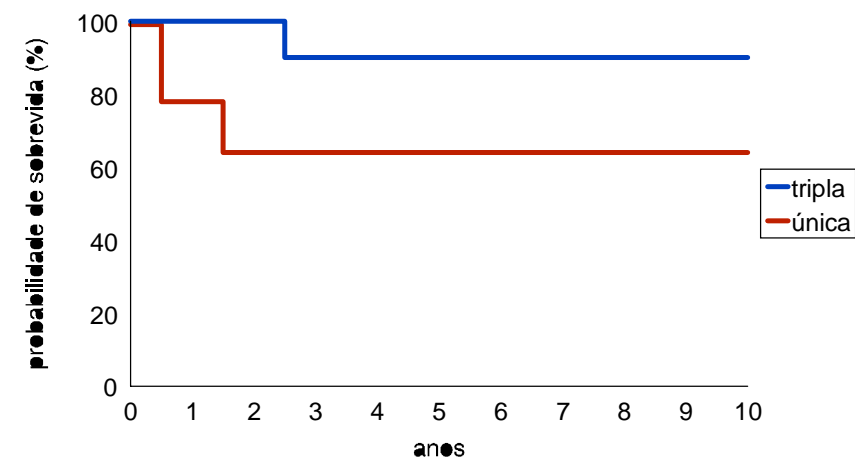

A - Estádio I $(p=0,1997)$

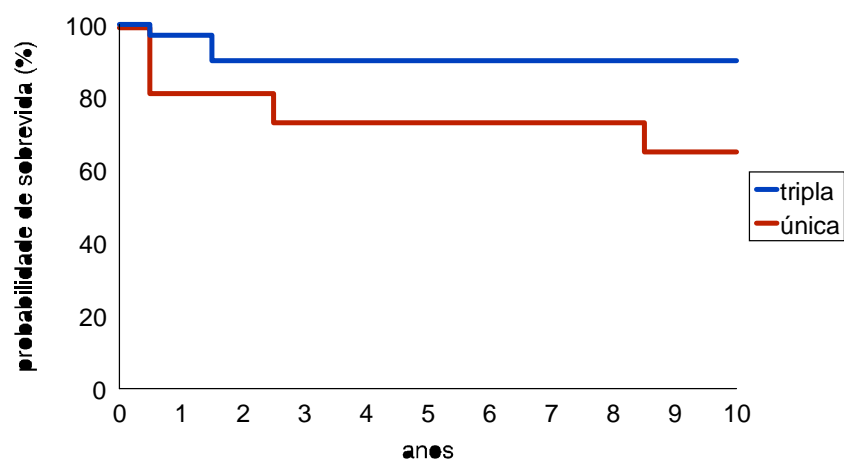

B - Estádio II $(p=0,1307)$

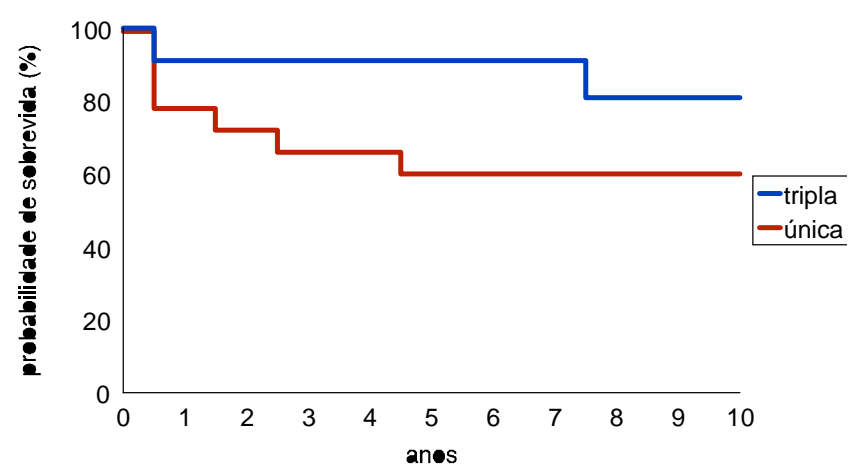

C - Estádio III ( $p=0,1747)$.

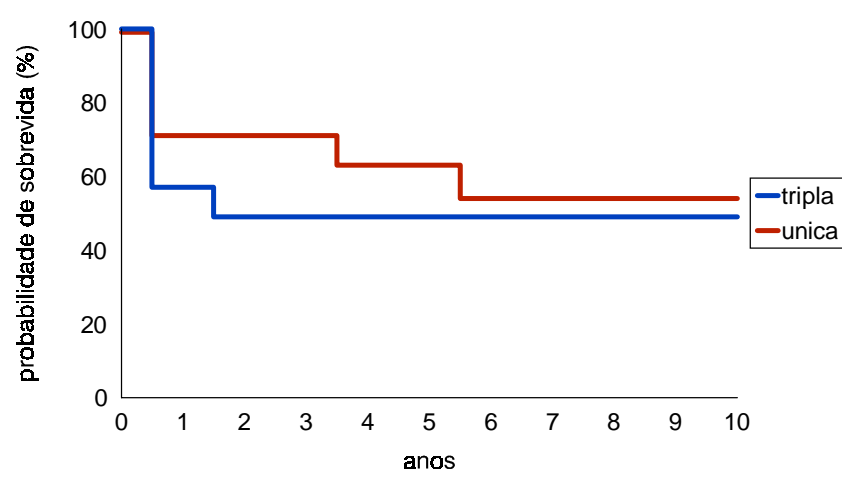

D - Estádio IVa $(p=0,6889)$

Figura 3 - Taxa acumulada de sobrevida livre de doença segundo o tipo de incisão e o estádio.

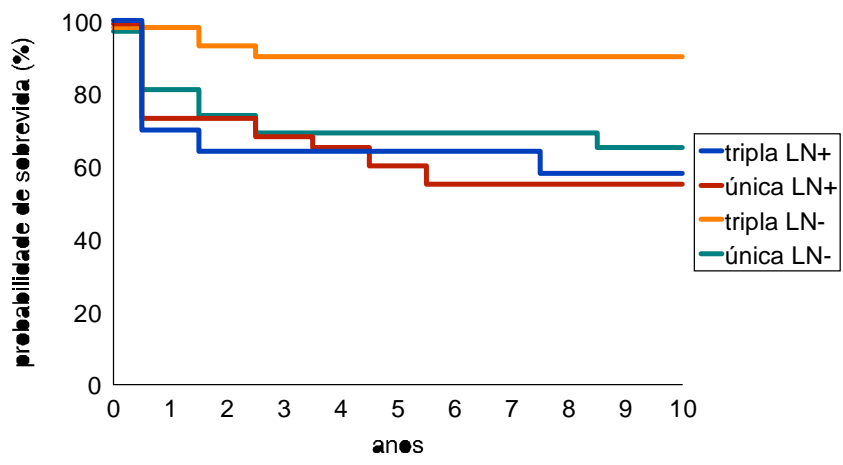

Figura 4 - Taxa acumulada de sobrevida livre de doença segundo o tipo de incisão e 0 estado dos linfonodos $(p=0,0132)$
Tabela 5 - Análise de sobrevida com covariadas - modelo de Cox.

Variável dependente: tempo livre de doença. Modelo final:

Variável

Coeficiente Erro-padrão Odds-ratio

\begin{tabular}{llll} 
Linfonodos comprometidos $\quad 1,2075$ & 0,3536 & 3,3450 \\
\hline
\end{tabular}

Variável dependente: tempo de sobrevida. Modelo final: Variável

Coeficiente Erro-padrão Odds-ratio

Linfonodos comprometidos

2,0781

1,0802

7,9890 


\section{Discussão}

Os resultados deste estudo permitem afirmar que a cirurgia por três incisões foi tão ou mais eficaz para tratar câncer de vulva do que a cirurgia por incisão única. A ocorrência de deiscências e os procedimentos secundários decorrentes das complicações pós-operatórias foram significativamente menores nas pacientes submetidas à cirurgia por três incisões. Além disso, o tempo de internação foi, também, significativamente menor nessas pacientes. Por outro lado, a principal justificativa para indicação da cirurgia com incisão única, em monobloco, é o menor índice de recidivas que se observaria com esse procedimento ${ }^{14}$. Neste estudo, as pacientes tratadas com três incisões apresentaram recidivas em proporção significativamente menor que as operadas por incisão única.

Nosso trabalho procurou comparar as duas técnicas cirúrgicas controlando as variáveis, relacionadas ao estado da paciente e as características tumorais pré-operatórias que poderiam levar a confusão na análise. A distribuição das pacientes segundo a idade, hábito de fumar, presença de síndromes clínicas, tipo e grau histológico e estádio patológico foi semelhante nos dois grupos e apenas a proporção de pacientes apresentando tumores com invasão de estruturas anatômicas perineais (pT3) foi maior naquelas tratadas com incisão única. Além disso, o número de pacientes submetidas à vulvectomia com uma ou três incisões é praticamente igual. Portanto, os resultados obtidos podem ser considerados decorrentes da técnica cirúrgica diferente que foi empregada em cada grupo.

Comparamos sempre a mesma cirurgia, sem variações de técnica. Em estudos anteriores foram utilizadas diferentes técnicas de abordagem cirúrgica, principalmente no que se refere à vulva e ao fechamento da incisão e os autores incluíam no grupo de três incisões, pacientes que tiveram a vulva tratada com exérese ampla, hemivulvectomia ou vulvectomia ${ }^{12,18}$. Também a linfadenectomia inguinal, neste estudo, foi realizada de forma completa - bilateral, superficial e profunda - em todos os casos. Nos estudos anteriores essa abordagem era muito heterogênia. A indicação da linfadenectomia era tanto mais conservadora quanto mais precoce o estádio. Eram consideradas da mesma forma linfadenectomia uni ou bilaterais, superficiais, profundas e, às vezes, pélvicas, todas compondo um mesmo grupo de pacientes de acordo com a incisão empregada ${ }^{12,14}$. O fechamento primário foi utilizado em todos os casos sendo que outros autores consideraram num mesmo grupo pacientes que tiveram a incisão fechada por sutura primária, rotações de retalhos e enxertos, que eram indicados pela necessidade no momento do fechamento $^{12,19}$.

O índice de deiscências foi alto: $83 \%$, sendo menos freqüente nas pacientes submetidas à cirurgia com três incisões. Helm et cols. ${ }^{12}$, analisando 64 pacientes observaram uma taxa total de deiscência de 39\%, com uma incidência 15\% menor nas tratadas com três incisões. Hopkins e cols. ${ }^{14}$, em 136 mulheres, tiveram $75 \%$ de deiscência, sendo esse índice de $31 \%$ nas pacientes submetidas à cirurgia por três incisões. As taxas totais de deiscências desses autores são menores que as observadas neste estudo e os recursos de cirurgia plástica podem diminuir tal complicação e devem ser utilizados de maneira individualizada.

A amplitude da cirurgia, contaminação bacteriana própria da área, infecção dos tumores exofíticos, tendência à necrose das dissecções cutâneas nos membros e freqüentes infecções secundárias são fatores que determinam complicações em graus variados de gravidade. A deiscência prolonga em muito a permanência hospitalar das pacientes, que varia de 30 a 50 dias, em média ${ }^{7}$. Neste estudo a permanência hospitalar das pacientes tratadas com três incisões foi menor que o descrito na literatura, sendo duas vezes menor que o das operadas por incisão única. Ao passo que as mulheres em que foram realizadas três incisões tiveram média de internação de 19,4 dias (DP $\pm 11,7$ ), as mulheres com incisão única tiveram 38,7 dias ( $\mathrm{DP} \pm 22,3$ ).

As recidivas nas pontes cutâneas entre as três incisões era o principal motivo para a indicação de incisão única nos estádios avançados. Julgava-se que a cirurgia por três incisões somente deveria ser indicada nos estádios iniciais $^{12,14,20}$. Demonstrou-se que a cirurgia por três incisões não teve maior índice de recidivas que aquelas realizadas com uma incisão. Neste estudo, $27 \%$ das pacientes apresentaram recidiva, sendo a vulvar quase duas vezes mais freqüente nas pacientes tratadas com incisão única. Nenhuma das pacientes submetidas à vulvectomia por três incisões apresentou recidiva inguinal. Aproximadamente dois terços das recidivas ocorreram nos dois primeiros anos após a cirurgia, sendo o intervalo livre de doença semelhante nos dois grupos -21 meses (DP \pm 19 ) nas incisões únicas e 16 meses $(D P \pm 13)$ nas incisões triplas.

O principal fator de mau prognóstico foi a invasão linfonodal, que permaneceu como fator independente da incisão, relacionada tanto com um menor tempo livre de doença quanto com uma menor sobrevida total. Os fatores que podem indicar maior probabilidade de invasão linfonodal são o estádio clínico, grau de diferenciação, invasão vascular e profundidade de invasão do tumor 
primário. O valor da positividade dos linfonodos em determinar um pior prognóstico foi confirmado por muitos autores. Além da invasão neoplásica, quanto maior o número ou o tamanho dos linfonodos acometidos, pior o prognóstico ${ }^{3,8,9,17}$. A sobrevida em cinco anos é de cerca de $90 \%$ quando os linfonodos são negativos, independentemente do estádio. Entretanto, cai para taxas que variam de 60 a $25 \%$ nos casos com linfonodos positivos ${ }^{5,16}$.

A percentagem de pacientes portadoras de câncer ressecável da vulva que apresentam metástases para linfonodos regionais gira entre 21 e $36 \%{ }^{10}$. Essa percentagem varia de acordo com o tumor primário, sendo de $10,7 \%$ nos tumores de até $2 \mathrm{~cm}, 26,2 \%$ nos tumores maiores que $2 \mathrm{~cm}$ restritos à vulva, e bem mais alta nos estádios mais avançados, sendo superior a $64,2 \%$ quando o tumor, de qualquer tamanho, invade a uretra, vagina ou ânus. Esses dados mostram a importância da abordagem das regiões inguinais no planejamento terapêutico das pacientes com câncer da vulva.

Concluímos que as complicações pósoperatórias imediatas, o tempo de internação e a necessidade de procedimentos secundários foram significativamente menos freqüentes nas pacientes submetidas à cirurgia por três incisões. As complicações pós-operatórias tardias foram pouco freqüentes e incidiram de forma semelhante independentemente do tipo de cirurgia. O tempo livre de doença e a taxa de recidiva não foram influenciados pelo tipo de incisão, sendo que o único fator associado com o prognóstico foi a invasão linfonodal. Assim, consideramos que as pacientes operáveis com carcinoma epidermóide da vulva podem ser tratadas com vulvectomia com três incisões independentemente do estádio.

\section{SUMMARY}

The purpose of the present study was to compare postoperative complications and recurrence rates in 132 women with invasive vulvar carcinoma treated by radical vulvectomy and bilateral groin lymphadenectomy performed with one or three incisions. It was a nonrandomized retrospective clinical study, including 65 women operated using a single incision and 67 with three incisions, between 1986 and 1996. Fischer's, chisquare, Student's t tests followed by logistic regression were used for statistical analysis as well as survival curves by the Kaplan-Meyer method, compared using Wilcoxon test, followed by Cox regression, with the statistical significance limit of 5\%. The groups were similar regarding age, smoking, presence of other diseases, histologic type and grade. Pathologic stage III was significantly more frequent in the single incision group, while free lymph nodes were more frequent in the three-incision group. The patients treated with triple incision showed statistically less frequent immediate complications ( $76 \%$ vs $92 \%, p<0.05)$, less dehiscence ( $72 \%$ vs $92 \%, p<0.01$ ), and shorter mean hospital stay (19.4 days vs 38.7 days, $p<0.001)$ and secondary procedures were less necessary ( $76 \%$ vs $94 \%, p<0.01)$. Seven postoperative deaths were observed: five with single incision and two with triple incision. Recurrence rate was statistically lower in patients treated with triple incision (19\% vs $35 \%, p<0.01)$ and with negative lymph nodes (6\% vs $15 \%, p<0.01$ ). After Cox regression, only positive lymph nodes had negative influence on disease-free survival. We concluded that vulvectomy using three incisions shows less complications than single incision, without compromising therapeutic efficacy, independently of the stage of the disease.

KEY WORDS: Vulvar carcinoma. Surgical complication. Surgical infection.

\section{Referências bibliográficas}

1. Abrão FS, Abrão MS. Câncer da vulva - diagnóstico, epidemiologia e estadiamento. In: Abrão FS, ed. Tratado de oncologia genital e mamária. São Paulo: Ed. Roca; 1995. p.474-88.

2. Ansink AC, Van Tinteren H, Aartsen EJ, Heintz APM. Outcome, complications and follow-up in surgically treated squamous cell carcinoma of the vulva 1956 - 1982. Eur J Obstet Gynecol Repr Biol 1991; 42:137-43.

3. Ayhan A, Tuncer R, Yucel I, Zeyneloglu HB, Kucukali T, Develioglu O. Risk factors for groin node metastasis in squamous carcinoma of the vulva: a multivariate analysis of 39 cases. Eur $\mathbf{J}$ Obstet Gynecol Reprod Biol 1993; 48:33-6.

4. Chakalova G, Karagiosov A. The surgical management of recurrent carcinoma of the vulva. Eur $\mathbf{J}$ Gynaecol Oncol 1993; 14:318-22.

5. Disaia PJ, Creasman WT. Invasive cancer of the vulva. In: Disaia PJ, Creasman WT, Mosby; Clinical gynecologic oncology. 3th ed. St Louis: 1989, p. 241-72.

6. Farias-Eisner R, Berek JS. Current management of squamous carcinoma of the vulva. Clin Geriatr Med 1993; 9:131-43.

7. Fisher LD, Van Belle G. Statistical methods in medical research. New York: John Wiley \& Sons; 1993.

8. Frankman O. Stage III squamous cell carcinoma of the vulva - results of a Swedish study. J Reprod Med 1991; 36:108-12.

9. Gomes-Rueda N, Vighi S, Garcia A, Cardinal L, Belardi 
MG, Di Paola G. Histologic predictive factors therapeutic impact in vulvar cancer. J Reprod Med 1994; 39:71-6.

10.Hacker NF, Van Der Velden J. Conservative management of early vulvar cancer. Cancer 1993; 71(suppl. 4):1673-7.

11.Heaps JM, FU YS, Montz J, Hacker NF, Berek JS. Surgical-pathologic variables predictive of local recurrence in squamous cell carcinoma of the vulva. Gynecol Oncol 1990; 38:309-14.

12.Helm CW, Hatch K, Austin JM, Partridge EE, Soong SJ, Elder JE et al. A matched comparison of single and triple incision techniques for the surgical treatment of carcinoma of the vulva. Gynecol Oncol 1992; 46:150-6.

13.Hopkins MP, Reid GC, Johnston CM, Morley GW. A comparison of staging systems for squamous cell carcinoma of the vulva. Gynecol Oncol 1992; 47:34-7.

14.Hopkins MP, Reid GC, Morley GW. Radical vulvectomy - the decision for the incision. Cancer 1993; 72:799-803.

15.Levato F, Bianchi A, Lenzi B, Pansini F, Randazzo F, Ferretti S et al. Surgical treatment of invasive carcinoma of the vulva: a reappraisal. Eur $\mathbf{J}$ Gynaecol Oncol 1992; 13(suppl 1):99-104.

16.Miecznikowski A \& Starzewski J. Surgical treatment of vulvar cancer. Eur J Gynaecol Oncol 1993; 14:392-7.
17. Onnis A, Marchetti M, Maggino T. Carcinoma of the vulva: critical analysis of survival and treatment of recurrences. Eur J Gynaecol Oncol 1992; 13:480-5.

18.Siller BS, Alvarez RD, Conner WD, Mccullough CH, Kilgore LC, Partridge EE et al. T2/3 vulvar cancer: a case-control study of triple versus en bloc radical vulvectomy and inguinal lymphadenectomy. Gynecol Oncol 1995; 57:335-9.

19.Souen JS, Filassi JR, Chin HC, Motta EV. Câncer de vulva na clínica ginecológica da Faculdade de Medicina da Universidade de São Paulo. Rev Bras Ginecol Obstet 1992; 14:87-92.

20.Sutton GP, Miser MR, Stehman FB, Look KY, Ehrlich $\mathrm{CE}$. Trends in the operative management of invasive squamous carcinoma of the vulva at Indiana University, 1974 to 1988. Am J Obstet Gynecol 1991; 164:1472-81.

21.Taussig FJ. Cancer of the vulva: an analysis of 155 cases (1911 - 1940). Am J Obstet Gynecol 1940; 40:764-79.

22.Verdiani LA, Derchain SFM, Juliato CRT. Vulvar carcinoma: epidemiology and clinical aspects. In: Convenção Latino-Americana da European School Of Oncology, II, São Paulo, 1997. Abstracts. São Paulo: Comitê Brasileiro da ESO; 1997. (Abstract, 29 - B2).

23.Way S. The anatomy of the lymphatic drainage of the vulva and its influence on the radical operation for carcinoma. Ann R Coll Surg Engl 1948; 3:187-209. 